\title{
Allied Disorders and Complications of Rheumatoid Arthritis - A Statistical Comorbidity Study of 234 Autopsy Patients
}

\section{Bely $\mathbf{M}^{1 *}$ and Apathy $\mathrm{A}^{2}$}

${ }^{1}$ Department of Pathology, Hospital of the Order of the Brothers of Saint John of God, Hungary

${ }^{2}$ Department of Rheumatology, St. Margaret Clinic, Hungary

*Corresponding author: Miklos Bely, Department of Pathology, Hospital of the Order of the Brothers of Saint John of God, H- 1027 Budapest, Frankel L. 17-19, Hungary, Tel: (361)4388491, (06-30) 2194142; Email: dr.bely.miklos@gmail.hu

\section{Abstract}

Objective: The incidence of co-morbidities is higher in rheumatoid arthritis (RA) than in the general population. Associated diseases accompanying RA may modify the clinical course and symptoms of RA and may influence the prevalence and mortality of complications related to the basic diseases and vica versa. The aim of this study was to determine statistically the possible effect of certain allied disorders: type 2 diabetes mellitus (DM), atherosclerosis (Ath), hypertension (HT), tuberculosis (Tb) with miliary dissemination (mTb), and malignant tumours (mTu) on the prevalence and mortality of RA related complications: systemic autoimmune vasculitis (AV), AA amyloidosis (AAa), lethal cardiac insufficiency (CI) caused by endo-, myo- or pancarditis, with or without interstitial pneumonitis, furthermore lethal septic infection (SI) combined with septic vasculitis (SV) or purulent arthritis (PA)

Patients and Methods: Twohundred thirty four (234) non- selected autopsy patients with RA were studied. RA was confirmed clinically according to the criteria of the American College of Rheumatology (ACR). The presence of DM, Ath, $\mathrm{HT}, \mathrm{Tb}, \mathrm{mTb}$, or mTu was determined and analyzed retrospectively, reviewing the clinical and pathological reports. The prevalence and mortality of AV, AAa, CI, SI, SV and PA was determined at autopsy and confirmed by a detailed review of extensive histological material. Demographics of different patient cohorts were compared with the Student (Welch) tprobe. The link between Ath, HT, DM, Tb, mTb, or mTu and AV, AAa, CI, SI, SV or PA was analyzed by Pearson's chisquared $(\chi 2)$ test.

Results: RA associated with DM in 41 (17.52\%), with severe Ath in 107 (45.72\%), with HT in 41 (17.52\%), with with Tb in 28 (11.96\%), including active disseminated mTb in 9 (3.85\%), and with mTu in 27 (11.54\%) of 234 patients. RA was complicated by AV in 43 (18.38 \%), by AAa in 48 (20.51\%), by CI in 15 (6.41\%), and by lethal SI in 33 (14.10\%) of 234 patients. SI was combined with PA in 15 (6.41\% of 234; 45.45\% of 33) or with SV in 7 (2.99\% of 234; 21.21\% of 33) patients; PA or SV did not occur without generalized SI. The relationship between Ath and AV, AV (lethal), AAa, AAa 


\section{Journal of Orthopedics \& Bone Disorders}

(lethal), CI, SI, PA or SV was consequently inverse and mostly significant. There was a positive and significant correlation between $\mathrm{Tb}$ or $\mathrm{mTb}$ and $\mathrm{AV}$, furthermore between $\mathrm{mTb}$ and mortality of $\mathrm{AV}$.

Discussion and Conclusions: The consequently inverse and (in most cases) significant correlation between atherosclerosis and autoimmune vasculitis, amyloidosis or sepsis shows that the prevalence or mortality of AV, AAa and SI was not influenced by Ath. RA patients with Ath may represent a special group, characterized by lower incidence of SV, $\mathrm{AAa}, \mathrm{SI}, \mathrm{CI}$, and carry a better prognosis. Ath is basically an age-dependent phenomenon, characteristically present in RA patients with advanced age, while AV, AAa (with or without lethal outcome) and SI are complications of RA, and characterize severe forms of disease, mostly in younger patients and with an earlier onset (without pronounced atherosclerosis). The positive and significant correlation between $\mathrm{Tb}$ or $\mathrm{mTb}$ and $\mathrm{AV}$ suggest a positive influence of $\mathrm{Tb}$ or $\mathrm{mTb}$ on the prevalence of vasculitis, e.g. the presence of $\mathrm{Tb}$ or endogenous exacerbation and miliary dissemination of $\mathrm{Tb}$ may promote the AV. The significant connection between $\mathrm{mTb}$ and mortality of AV indicates an increased risk of lethal outcome.

Keywords: Rheumatoid Arthritis; Allied Disorder; RA Related Complications; Statistical Analysis

Abbreviations: RA: Rheumatoid Arthritis; ARA: American College of Rheumatology; DM: Type 2 Diabetes Mellitus; Ath: Atherosclerosis; HT: Hypertension; Tb: Tuberculosis; mTb: Miliary Dissemination of Tuberculosis; mTu: Malignant Tumours; AV: Systemic Autoimmune Vasculitis; AAa: Systemic AA amyloidosis; CI: Lethal Cardiac Insufficiency; SI: Lethal Septic Infection; PA: Purulent Arthritis; SV: Systemic Septic Vasculitis; SD: Standard Deviation; ND: No Data; HE: Hematoxylin-Eosin Staining; PAS: Perjodic Acid Schiff Reaction.

\section{Introduction}

The incidence of co-morbidities (including "hypertension, dyslipidemia, myocardial infarction or angina, stroke, osteoarthritis, lung cancer, colon cancer, pulmonary tuberculosis, asthma, diabetes, depression, thyroid disease and chronic kidney disease") is higher in rheumatoid arthritis (RA) than in the general population [1]. According to van den Hoek, et al. (2017) the mortality in patients with rheumatoid arthritis is higher for cardiovascular, respiratory, musculoskeletal and digestive diseases than in the general population [2].

Associated diseases accompanying RA may modify the clinical course and symptoms of RA and may influence the prevalence and mortality of complications related to the basic diseases and vica versa [3].
The aim of this study was to determine statistically the possible effect of certain allied disorders: type 2 diabetes mellitus (DM), atherosclerosis (Ath), hypertension (HT), tuberculosis $(\mathrm{Tb})$ with miliary dissemination $(\mathrm{mTb})$, and malignant tumours (mTu) on the prevalence and mortality of RA related complications: systemic autoimmune vasculitis (AV), AA amyloidosis (AAa), lethal cardiac insufficiency (CI) caused by endo-, myo- or pancarditis, with or without interstitial pneumonitis, furthermore lethal septic infection (SI) combined with septic vasculitis (SV) or purulent arthritis (PA)

\section{Patients and Methods}

Twohundred thirty four (234) non- selected autopsy patients with RA were studied. RA was confirmed clinically according to the criteria of the American College of Rheumatology (ACR) [4].

The presence of DM, Ath, HT, Tb, mTb, or mTu was determined and analyzed retrospectively, reviewing the clinical and pathological reports. The prevalence and mortality of AV, AAa, CI, SI, SV and PA was determined at autopsy and confirmed by a detailed review of extensive histological material.

Demographics of different patient cohorts were compared with the Student (Welch) t-probe [5]. The link between Ath, HT, DM, Tb, mTb, or mTu and AV, AAa, CI, SI, SV or PA was analyzed by Pearson's chi-squared $(\chi 2)$ test [5]. 


\section{Journal of Orthopedics \& Bone Disorders}

\section{Glossary of Definitions}

- Allied disorder: important comorbidity associated with RA with or without direct causal role in death

- RA related complication: consequence of RA with or without direct causal role in death

Atherosclerosis was diagnosed in RA patients only in cases when it was present macroscopically as a "severe" atherosclerotic process (characterized by occlusive thrombosis or sclerotic ulcers) or when it was the basic disease leading to death. Moderate changes like hyaline or sclerotic plaques without causal role in death were not mentioned as "atherosclerosis" since such changes are frequent in elderly RA patients [3].

- "Prevalence" of vasculitis: concerns the presence of inflammatory infiltration and structural changes in blood vessels of different calibers

- Systemic vasculitis of autoimmune origin (AV): was defined as one of the basic manifestations of RA, excluding other causes of vasculitis, like hypertension, diabetes mellitus, tumors, septic infections etc. $[3,6]$.

- Systemic vasculitis of septic origin (SV) was defined as an important complication of generalized lethal septic infection (SI). The clinically identified pathogenic agents and the strong, significant and positive correlation between SV and SI supported the infectious origin of SV [3, 7].

- "Prevalence" of AAa: concerns the presence of amyloid A deposits in blood vessels of different calibers or in different tissue structures of various organs.

- AAa was diagnosed histologically according to Romhányi by a modified (more sensitive) Congo red staining $[8,9]$. Amyloid A deposits were identified in serial histologic sections by immunohistochemical and histo chemical methods [10].

\section{Results}

RA associated with DM in 41 (17.52\%), with severe Ath in 107 (45.72\%), with HT in 41 (17.52\%), with with $\mathrm{Tb}$ in 28 (11.96\%), including active disseminated $\mathrm{mTb}$ in 9 (3.85\%), and with mTu in 27 (11.54\%) of 234 patients.

Adult type 2 DM was clinically recognized and controlled in all cases and no patients died of it; the basic diseases leading to death were different in all RA patients associated with DM. Ath led directly to death in 61 (57.01\% of 107 and $26.06 \%$ of 234), HT in 2 of 41 , Tb with $\mathrm{mTb}$ in 3 of 28 , and mTu in 12 of 27 patients. In lethal cases only the influence of Ath was analyzed as a RA related complication; the others, because of their limited numbers were not tested.

RA was complicated by AV in 43 (18.38\%), by AAa in 48 (20.51\%), by CI with lethal outcome (caused exclusively by endo-, myo- or pancarditis with or without interstitial pneumonitis) in 15 (6.41\%), and by lethal SI in $33(14.10 \%)$ of 234 patients. SI was combined with PA in $15(6.41 \%$ of $234 ; 45.45 \%$ of 33$)$ or with SV in 7 (2.99\% of $234 ; 21.21 \%$ of 33 ) patients; PA or SV did not occur without generalized SI.

AV led to death in $24(10.25 \%)$, AAa in 20 (8.54\%) of 234 patients. The prevalence and mortality of CI, SI (with or without SV and PA) were identical, because only lethal cases were listed.

Demographics, onset and duration of RA associated with DM, Ath, HT, Tb, mTb and mTu or complicated by AV, $\mathrm{AAa}, \mathrm{CI}$ and SI (including PA or SV) are summarized in Table 1.

\begin{tabular}{|c|c|c|c|c|c|}
\hline Sex & $\begin{array}{l}\text { Number of } \\
\text { autopsies }\end{array}$ & $\begin{array}{c}\text { Mean age in years at } \\
\text { death } \pm \text { SD }\end{array}$ & $\begin{array}{c}\text { Range (in } \\
\text { years) }\end{array}$ & $\begin{array}{l}\text { Mean age at onset of } \\
\text { disease } \pm \text { SD }\end{array}$ & $\begin{array}{c}\text { Disease duration (in } \\
\text { years) mean } \pm S D\end{array}$ \\
\hline $\begin{array}{l}\text { RA patients } \\
\text { (total) }\end{array}$ & 234 & $66.25 \pm 13.15$ & $16-88$ & $51.02 \pm 16.58$ & $14.76 \pm 10.79$ \\
\hline Female & 170 & $66.31 \pm 12.82$ & $16-88$ & $50.46 \pm 15.92$ & $15.42 \pm 11.12$ \\
\hline Male & 64 & $66.08 \pm 13.97$ & $19-88$ & $52.55 \pm 18.18$ & $12.96 \pm 9.60$ \\
\hline With DM & 41 of 234 & $68.17 \pm 8.85$ & $47-83$ & $54.32 \pm 13.99$ & $15.10 \pm 10.67$ \\
\hline Female & 30 & $66.77 \pm 8.04$ & $47-82$ & $53.00 \pm 14.52$ & $15.13 \pm 11.74$ \\
\hline Male & 11 & $72.00 \pm 9.75$ & $48-83$ & $58.13 \pm 11.54$ & $15.00 \pm 6.69$ \\
\hline With Ath & 107 of 234 & $71.90 \pm 10.76$ & $47-88$ & $56.85 \pm 14.23$ & $14.43 \pm 11.56$ \\
\hline Female & 78 & $71.47 \pm 11.62$ & $47-88$ & $54.98 \pm 14.19$ & $15.94 \pm 12.36$ \\
\hline Male & 29 & $73.03 \pm 7.69$ & $56-88$ & $61.70 \pm 13.12$ & $10.50 \pm 7.90$ \\
\hline Ath (lethal) & 61 of 107 & $72.83 \pm 12.49$ & $47-88$ & $54.59 \pm 13.97$ & $17.05 \pm 12.45$ \\
\hline Female & 49 & $72.15 \pm 13.44$ & $47-88$ & $53.67 \pm 13.79$ & $17.61 \pm 13.01$ \\
\hline Male & 12 & $75.58 \pm 6.01$ & $64-84$ & $58.38 \pm 14.08$ & $14.75 \pm 9.47$ \\
\hline
\end{tabular}




\section{Journal of Orthopedics \& Bone Disorders}

\begin{tabular}{|c|c|c|c|c|c|}
\hline $\begin{array}{c}\text { Ath } \\
\text { (associated) }\end{array}$ & 46 of 107 & $70.67 \pm 7.86$ & $56-88$ & $59.84 \pm 14.00$ & $10.97 \pm 9.18$ \\
\hline Female & 29 & $70.34 \pm 7.63$ & $56-84$ & $57.26 \pm 14.59$ & $13.05 \pm 10.53$ \\
\hline Male & 17 & $71.24 \pm 8.21$ & $56-88$ & $63.92 \pm 11.93$ & $7.67 \pm 4.92$ \\
\hline With HT & 41 of 234 & $69.37 \pm 8.67$ & $47-86$ & $49.05 \pm 14.00$ & $19.14 \pm 9.18$ \\
\hline Female & 29 & $68.93 \pm 7.63$ & $47-86$ & $46.44 \pm 15.01$ & $21.06 \pm 12.43$ \\
\hline Male & 12 & $70.42 \pm 6.98$ & $59-82$ & $56.88 \pm 13.65$ & $13.38 \pm 7.73$ \\
\hline With Tb & 28 of 234 & $68.93 \pm 10.10$ & $47-84$ & $54.96 \pm 15.66$ & $14.33 \pm 12.14$ \\
\hline Female & 21 & $69.76 \pm 10.78$ & $47-84$ & $55.00 \pm 16.87$ & $15.30 \pm 13.28$ \\
\hline Male & 7 & $66.43 \pm 7.11$ & $56-78$ & $54.86 \pm 11.54$ & $11.57 \pm 7.40$ \\
\hline With mTb & 9 of 28 & $68.00 \pm 9.75$ & $50-82$ & $59.38 \pm 7.35$ & $9.75 \pm 4.89$ \\
\hline Female & 8 & $67.88 \pm 10.34$ & $50-82$ & $58.71 \pm 7.63$ & $10.43 \pm 4.87$ \\
\hline Male & 1 & $69.00 \pm 0.00$ & $69-69$ & $64.00 \pm 0.00$ & $5.00 \pm 0.00$ \\
\hline With mTu & 27 of 234 & $66.81 \pm 12.72$ & $34-87$ & $55.41 \pm 16.86$ & $11.64 \pm 8.04$ \\
\hline Female & 19 & $64.37 \pm 12.84$ & $34-81$ & $52.47 \pm 16.81$ & $11.41 \pm 8.23$ \\
\hline Male & 8 & $72.63 \pm 10.32$ & $53-87$ & $64.40 \pm 12.67$ & $12.40 \pm 7.31$ \\
\hline With AV & 43 of 234 & $68.26 \pm 10.80$ & $32-88$ & $56.85 \pm 15.24$ & $12.08 \pm 10.82$ \\
\hline Female & 26 & $68.96 \pm 11.84$ & $32-88$ & $58.04 \pm 13.68$ & $12.71 \pm 9.58$ \\
\hline Male & 17 & $67.12 \pm 8.84$ & $53-83$ & $55.06 \pm 17.16$ & $11.13 \pm 12.39$ \\
\hline AV (lethal) & 24 of 43 & $63.96 \pm 10.86$ & $32-82$ & $52.83 \pm 16.34$ & $12.52 \pm 11.96$ \\
\hline Female & 15 & $65.00 \pm 12.65$ & $32-82$ & $54.29 \pm 13.65$ & $13.07 \pm 9.25$ \\
\hline Male & 9 & $62.22 \pm 6.56$ & $53-72$ & $50.56 \pm 19.60$ & $11.67 \pm 15.20$ \\
\hline With AAa & 48 of 234 & $63.75 \pm 14.76$ & $19-88$ & $46.66 \pm 17.82$ & $17.18 \pm 9.85$ \\
\hline Female & 38 & $65.13 \pm 11.36$ & $32-88$ & $47.25 \pm 16.48$ & $17.75 \pm 10.55$ \\
\hline Male & 10 & $58.50 \pm 22.81$ & $19-88$ & $44.00 \pm 22.72$ & $14.63 \pm 5.02$ \\
\hline AAa (lethal) & 20 of 48 & $56.80 \pm 17.55$ & $19-88$ & $40.33 \pm 20.31$ & $17.28 \pm 9.44$ \\
\hline Female & 13 & $59.54 \pm 12.09$ & $32-75$ & $40.25 \pm 17.49$ & $18.67 \pm 10.74$ \\
\hline Male & 7 & $51.71 \pm 23.86$ & $19-88$ & $40.50 \pm 25.00$ & $14.50 \pm 5.02$ \\
\hline With CI & 15 of 234 & $66.67 \pm 15.45$ & $20-83$ & $56.17 \pm 18.99$ & $11.17 \pm 9.95$ \\
\hline Female & 9 & $69.56 \pm 10.19$ & $52-82$ & $61.14 \pm 17.50$ & $12.71 \pm 12.30$ \\
\hline Male & 6 & $62.17 \pm 20.18$ & $20-83$ & $49.20 \pm 18.80$ & $9.00 \pm 4.20$ \\
\hline With SI & 33 of 234 & $62.33 \pm 8.63$ & $41-83$ & $49.00 \pm 12.41$ & $13.45 \pm 9.04$ \\
\hline Female & 23 & $61.35 \pm 9.42$ & $41-83$ & $48.45 \pm 13.50$ & $13.20 \pm 9.65$ \\
\hline Male & 10 & $64.60 \pm 5.87$ & $52-71$ & $50.22 \pm 9.43$ & $14.00 \pm 7.48$ \\
\hline With PA & 15 of 33 & $59.47 \pm 7.03$ & $46-71$ & $44.08 \pm 10.45$ & $16.38 \pm 10.31$ \\
\hline Female & 10 & $58.20 \pm 6.69$ & $46-68$ & $42.88 \pm 10.84$ & $16.63 \pm 11.34$ \\
\hline Male & 5 & $62.00 \pm 7.01$ & $52-71$ & $46.00 \pm 9.49$ & $16.00 \pm 8.39$ \\
\hline With SV & 7 of 33 & $61.57 \pm 7.74$ & $51-70$ & $51.14 \pm 12.03$ & $10.43 \pm 8.78$ \\
\hline Female & 4 & $57.25 \pm 7.36$ & $51-69$ & $45.75 \pm 13.12$ & $11.50 \pm 11.15$ \\
\hline Male & 3 & $67.33 \pm 3.09$ & $63-70$ & $58.33 \pm 4.19$ & $9.00 \pm 3.27$ \\
\hline
\end{tabular}

Table 1: Sex, mean age with SD, range, onset and disease duration of RA patients associated with DM ( $\mathrm{n}=41)$, Ath ( $\mathrm{n}=107)$, HT $(n=41), T b(n=28), m T b(n=9)$ and $\mathrm{mTu}(\mathrm{n}=27)$ or complicated by AV $(\mathrm{n}=43)$, AAa $(\mathrm{n}=48), \mathrm{CI}(\mathrm{n}=15)$, SI $(\mathrm{n}=33)$ including PA ( $\mathrm{n}=15)$ or SV ( $\mathrm{n}=7)$.

\section{Glossary to Table 1:}

RA - Rheumatoid Arthritis

Lethal - allied disorder or RA related complication with lethal outcome

Associated - allied disorder (accompanying disease) without direct causal role in death

DM - type 2 Diabetes Mellitus; Ath: Atherosclerosis; HT: HyperTension; Tb: Tuberculosis; mTb: miliary Tuberculosis; mTu: malignant Tumors; AV: systemic Autoimmune Vasculitis; AAa: systemic AA amyloidosis; CI: Cardiac Insufficiency with lethal outcome; SI: lethal Septic Infection; PA: Purulent Arthritis; SV: systemic Septic Vasculitis; SD: Standard deviation 


\section{Journal of Orthopedics \& Bone Disorders}

Comparing the mean age of female and male RA patients $(n=234)$ associated with $\mathrm{DM}, \mathrm{Ath}, \mathrm{HT}, \mathrm{Tb}, \mathrm{mTb}$ and mTu or complicated by AV, AAa, CI and SI (including $\mathrm{PA}$ or SV) to the mean age of total population, there was no significant difference between patient cohorts except RA patients with Ath, lethal AAa, and SI including PA.

The mean age of RA patients associated with Ath $(\mathrm{n}=107)$ was significantly higher $(71.90$ years versus 66.25 ; $\mathrm{p}<0.0000015)$, both of females (71.47 years versus 66.31; $\mathrm{p}<0.00014)$ and males (73.03 years versus 66.08 ; $\mathrm{p}<0.003)$.

Comparing the subgroups of Ath (lethal outcome $n=61$ of 107, and coexistent associated disease $n=46$ of 107) with the mean age of the total population $(n=234)$, the tendency was the same only the levels of difference were disparate:

The mean age of RA patients with lethal outcome of Ath $(\mathrm{n}=61)$ was significantly higher $(72.83$ years versus 66.25 ; $p<0.0000043$ ), for both females (72.15 years versus $66.31 ; \mathrm{p}<0.00036)$ and males $(75.58$ years versus 66.08; $\mathrm{p}<0.001$ ), and the mean age of RA patients with coexistent associated Ath $(\mathrm{n}=46)$ was significantly higher (70.67 years versus 66.25; $\mathrm{p}<0.003$ ), and it was the same in women (70.34 years versus $66.31 ; \mathrm{p}<0.022$ ). The mean age of males was higher than the mean age of total population (71.24 years versus 66.08; $p<0.063-\mathrm{NS}$ ), but this difference was not significant (Tables $1 \& 2$ ).

Comparing the onset of RA and duration of disease there was a collateral (parallel) tendency between RA patients $(n=234)$ with $\mathrm{mTb}(\mathrm{n}=9)$ or AV $(\mathrm{n}=43)$.

RA started later in patients with mTb (59.38 years versus 51.02; $\mathrm{p}<0.033$ ), who died earlier (9.75 years versus 14.36; $\mathrm{p}<0.563 ; \mathrm{p}<0.020$ ), and it was the same in women (58.71 years versus 50.46; $\mathrm{p}<0.050$, and 10.43 years versus 15.42; $\mathrm{p}<0.040$ ).

RA patients with complications of $A V(n=43)$ showed a similar predisposition as patients with mTb. RA started later in patients with AV (56.85 years versus 51.02; p< 0.037), who died earlier (9.75 years versus 14.36; $\mathrm{p}<$ 0.167 - NS), but the latter was not significant. The tendency was similar both in women (onset of RA: 58.04 years versus 50.46; $p<0.022$, and duration of disease: 10.43 years versus $15.42 \mathrm{p}<0.230-\mathrm{NS}$ ) and men (onset of RA: 55.06 years versus 52.55; $\mathrm{p}<0.630-\mathrm{NS}$, and duration of disease: 11.13 years versus 12.96; $p<0.604-$ NS), but partly without significant relationship.

The mean age of RA patients with lethal AAa $(n=20)$ was lower (56.80 years versus 66.25; $\mathrm{p}<0.032$ ), and RA started significantly earlier (40.33 years versus 51.02; $\mathrm{p}<$ $0.049)$, than in the general population $(n=234)$.

The mean age of RA patients with SI $(n=33)$ or PA $(n=15)$ was significantly lower collate to the average of total population (62.33 or 59.47 years versus 66.25 ; $\mathrm{p}<$ 0.028 or $\mathrm{p}<0.004$ ). The mean age of females complicated by SI $(n=23)$ or PA $(n=10)$ was significantly lower as well ( 61.35 or 58.20 years versus 66.31 or 66.08 ; $p<0.031$ or $\mathrm{p}<0.005)$. The mean age of males complicated by SI $(\mathrm{n}=10)$ or PA $(n=5)$ was lower also (64.60 or 62.00 years versus 66.08; $\mathrm{p}<0.579$ - NS or $\mathrm{p}<0.337$ - NS), but these differences were not significant.

The statistical links ("p" values of significance) between RA patients with DM, Ath, HT, Tb, mTb, mTu or complicated by AV, AAa, SI (including PA or SV) are summarized in Table 2.

\begin{tabular}{|c|c|c|c|}
\hline RA patients n=234 & Age & Onset of disease & Disease Duration \\
\hline RA pts. $\mathbf{n}=\mathbf{2 3 4}$ versus pts. with DM $\mathbf{n}=\mathbf{4 1}$ of $\mathbf{2 3 4}$ & $\mathbf{p}<\mathbf{0 , 2 4 0}$ & $\mathbf{p}<\mathbf{0 , 2 5 1}$ & $\mathbf{p}<\mathbf{0 , 8 7 3}$ \\
\hline Female $\mathrm{n}=\mathbf{1 7 0}$ of 164 versus $\mathrm{n}=\mathbf{3 0}$ of 41 & $\mathrm{p}<0,797$ & $\mathrm{p}<0,459$ & $\mathrm{p}<0,915$ \\
\hline Male $\mathrm{n}=\mathbf{6 4}$ of 164 versus $\mathrm{n}=\mathbf{1 1}$ of 41 & $\mathrm{p}<0,113$ & $\mathrm{p}<0,294$ & $\mathrm{p}<0,493$ \\
\hline RA pts. $\mathbf{n = 2 3 4}$ versus pts. with Ath $\mathbf{n}=\mathbf{1 0 7}$ of $\mathbf{2 3 4}$ & $\mathbf{p}<\mathbf{0 , 0 0 0 0 0}$ & $\mathbf{p}<\mathbf{0 , 0 0 6}$ & $\mathbf{p}<\mathbf{0 , 8 7 3}$ \\
\hline Female $\mathrm{n}=\mathbf{1 7 0}$ of 164 versus $\mathrm{n}=\mathbf{7 8}$ of 107 & $\mathbf{p}<\mathbf{0 , 0 0 0 1 4}$ & $\mathrm{p}<0,065$ & $\mathrm{p}<0,793$ \\
\hline Male $\mathrm{n}=\mathbf{6 4}$ of 164 versus n=29 of 107 & $\mathrm{p}<\mathbf{0 , 0 0 3}$ & $\mathrm{p}<0,287$ & $\mathrm{p}<\mathbf{0 , 0 2 6}$ \\
\hline RA pts. $\mathbf{n = 2 3 4}$ versus pts. Ath (lethal) $\mathbf{n}=\mathbf{6 1}$ of $\mathbf{1 0 7}$ & $\mathbf{p}<\mathbf{0 , 0 0 0 0 0}$ & $\mathbf{p}<\mathbf{0 , 1 6 4}$ & $\mathbf{p}<\mathbf{0 , 2 8 6}$ \\
\hline Female $\mathrm{n}=\mathbf{1 7 0}$ of 164 versus $\mathrm{n}=\mathbf{4 9}$ of 61 & $\mathbf{p}<\mathbf{0 , 0 0 0 3 6}$ & $\mathrm{p}<0,258$ & $\mathrm{p}<0,386$ \\
\hline Male $\mathrm{n}=\mathbf{6 4}$ of 164 versus $\mathrm{n}=\mathbf{1 2}$ of 61 & $\mathbf{p}<\mathbf{0 , 0 0 1}$ & $\mathrm{p}<0,348$ & $\mathrm{p}<0,652$ \\
\hline RA pts. $\mathbf{n = 2 3 4}$ versus pts. Ath (associated) $\mathbf{n}=\mathbf{4 5}$ of $\mathbf{1 0 7}$ & $\mathbf{p}<\mathbf{0 , 0 0 3}$ & $\mathbf{p}<\mathbf{0 , 0 0 3}$ & $\mathbf{p}<\mathbf{0 , 0 4 7}$ \\
\hline Female $\mathrm{n}=\mathbf{1 7 0}$ of 164 versus $\mathrm{n}=\mathbf{7}$ of 45 & $\mathbf{p}<\mathbf{0 , 0 2 2}$ & $\mathrm{p}<0,079$ & $\mathrm{p}<0,283$ \\
\hline Male $\mathrm{n}=\mathbf{6 4}$ of 164 versus $\mathrm{n}=\mathbf{2}$ of 45 & $\mathrm{p}<0,063$ & $\mathbf{p}<\mathbf{0 , 0 1 7}$ & $\mathbf{p}<\mathbf{0 , 0 1 4}$ \\
\hline RA pts. $\mathbf{n = 2 3 4}$ versus pts. with $\mathbf{H T} \mathbf{n}=\mathbf{4 1}$ of $\mathbf{2 3 4}$ & $\mathbf{p}<\mathbf{0 , 0 5 5}$ & $\mathbf{p}<\mathbf{0 , 5 1 7}$ & $\mathbf{p}<\mathbf{0 , 0 6 2}$ \\
\hline
\end{tabular}




\section{Journal of Orthopedics \& Bone Disorders}

\begin{tabular}{|c|c|c|c|}
\hline Female $n=\mathbf{1 7 0}$ of 164 versus $n=\mathbf{2 9}$ of 41 & $\mathrm{p}<0,191$ & $\mathrm{p}<0,249$ & $\mathrm{p}<0,050$ \\
\hline Male $n=\mathbf{6 4}$ of 164 versus $n=12$ of 41 & $\mathrm{p}<0,125$ & $\mathrm{p}<0,471$ & $\mathrm{p}<0,900$ \\
\hline RA pts. $n=234$ versus pts. with $T b n=28$ of 234 & $\mathbf{p}<0,212$ & $\mathrm{p}<0,242$ & $\mathrm{p}<0,867$ \\
\hline Female $n=\mathbf{1 7 0}$ of 164 versus $n=\mathbf{2 1}$ of 28 & $\mathrm{p}<0,193$ & $\mathrm{p}<0,280$ & $\mathrm{p}<0,970$ \\
\hline Male $n=64$ of 164 versus $n=7$ of 28 & $\mathrm{p}<0,920$ & $p<0,678$ & $p<0,686$ \\
\hline RA pts. $n=234$ versus pts. with $m$ Tb $n=9$ of 234 & $p<0,634$ & $\mathbf{p}<0,033$ & $\mathrm{p}<0,020$ \\
\hline Female $\mathrm{n}=\mathbf{1 7 0}$ of 164 versus $\mathrm{n}=\mathbf{8}$ of 9 & $\mathrm{p}<0,708$ & $\mathbf{p}<\mathbf{0 , 0 5 0}$ & $\mathrm{p}<0,040$ \\
\hline Male $n=64$ of 164 versus $n=1$ of 9 & - & - & - \\
\hline RA pts. $n=234$ versus pts. with $\mathrm{mTu} n=27$ of 234 & $\mathbf{p}<\mathbf{0 , 8 3 2}$ & $\mathbf{p}<0,269$ & $\mathrm{p}<0,116$ \\
\hline Female $n=\mathbf{1 7 0}$ of 164 versus $n=19$ of 27 & $\mathrm{p}<0,545$ & $\mathrm{p}<0,654$ & $\mathrm{p}<0,091$ \\
\hline Male $n=\mathbf{6 4}$ of 164 versus $n=8$ of 27 & $\mathrm{p}<0,157$ & $\mathrm{p}<0,115$ & $\mathrm{p}<0,892$ \\
\hline RA pts. $n=234$ versus pts. with $A V n=43$ of 234 & $\mathbf{p}<0,285$ & $\mathrm{p}<0,037$ & $\mathrm{p}<0,165$ \\
\hline Female $n=\mathbf{1 7 0}$ of 164 versus $n=\mathbf{2 6}$ of 43 & $\mathrm{p}<0,304$ & $\mathrm{p}<0,022$ & $\mathrm{p}<0,230$ \\
\hline Male $n=\mathbf{6 4}$ of 164 versus $n=\mathbf{1 7}$ of 43 & $\mathrm{p}<0,715$ & $\mathrm{p}<0,630$ & $\mathrm{p}<0,604$ \\
\hline RA pts. $n=234$ versus pts. with AV (lethal) $n=24$ of 234 & $p<0,348$ & $p<0,629$ & $\mathrm{p}<0,410$ \\
\hline Female $n=\mathbf{1 7 0}$ of 164 versus $n=\mathbf{1 5}$ of 24 & $p<0,713$ & $p<0,356$ & $p<0,404$ \\
\hline Male $n=\mathbf{6 4}$ of 164 versus $n=9$ of 24 & $p<0,201$ & $p<0,793$ & $p<0,821$ \\
\hline RA pts. $n=234$ versus pts. with AAa $n=48$ of 234 & $\mathrm{p}<0,281$ & $\mathrm{p}<0,149$ & $\mathrm{p}<0,159$ \\
\hline Female $\mathrm{n}=\mathbf{1 7 0}$ of 164 versus $\mathrm{n}=\mathbf{3 8}$ of 48 & $\mathrm{p}<0,572$ & $\mathrm{p}<0,307$ & $\mathrm{p}<0,256$ \\
\hline Male $n=\mathbf{6 4}$ of 164 versus $n=\mathbf{1 0}$ of 48 & $\mathrm{p}<0,354$ & $\mathrm{p}<0,368$ & $\mathrm{p}<0,489$ \\
\hline RA pts. $n=234$ versus pts. with AAa (lethal) $n=20$ of 234 & $\mathrm{p}<0,032$ & $\mathrm{p}<0,049$ & $\mathrm{p}<0, \mathbf{0 1 1}$ \\
\hline Female $n=\mathbf{1 7 0}$ of 164 versus $n=\mathbf{1 3}$ of 20 & $\mathrm{p}<0,082$ & $\mathrm{p}<0,085$ & $\mathrm{p}<0,354$ \\
\hline Male $n=64$ of 164 versus $n=7$ of 20 & $\mathrm{p}<0,194$ & $\mathrm{p}<0,338$ & $\mathrm{p}<0,573$ \\
\hline RA pts. $n=234$ versus pts. with $\mathrm{CI} n=15$ of 234 & $\mathrm{p}<0,923$ & $p<0,397$ & $\mathrm{p}<0,269$ \\
\hline Female $\mathrm{n}=\mathbf{1 7 0}$ of 164 versus $\mathrm{n}=\mathbf{9}$ of 15 & $\mathrm{p}<0,405$ & $\mathrm{p}<0,189$ & $\mathrm{p}<0,614$ \\
\hline Male $n=64$ of 164 versus $n=6$ of 15 & $\mathrm{p}<0,687$ & $\mathrm{p}<0,746$ & $\mathrm{p}<0,153$ \\
\hline RA pts. $n=234$ versus pts. with SI $n=33$ of 234 & $\mathrm{p}<0,028$ & $\mathrm{p}<0,449$ & $\mathrm{p}<0,491$ \\
\hline Female $n=\mathbf{1 7 0}$ of 164 versus $n=\mathbf{2 3}$ of 33 & $\mathrm{p}<0,031$ & $\mathrm{p}<559$ & $p<0,366$ \\
\hline Male $n=\mathbf{6 4}$ of 164 versus $n=\mathbf{1 0}$ of 33 & $\mathrm{p}<0,579$ & $\mathrm{p}<0,589$ & $\mathrm{p}<0,733$ \\
\hline RA pts. $n=234$ versus pts. with $P A n=15$ of 234 & p< 0,004 & $\mathbf{p}<0,049$ & $\mathrm{p}<0,606$ \\
\hline Female $\mathrm{n}=\mathbf{1 7 0}$ of 164 versus $\mathrm{n}=\mathbf{1 0}$ of 15 & $\mathrm{p}<0,005$ & $\mathrm{p}<0,115$ & $\mathrm{p}<0,791$ \\
\hline Male $n=64$ of 164 versus $n=5$ of 15 & $\mathrm{p}<0,337$ & $\mathrm{p}<0,267$ & $\mathrm{p}<0,522$ \\
\hline RA pts. $n=234$ versus pts. with SV $n=7$ of 234 & $\mathrm{p}<0,196$ & $\mathrm{p}<0,982$ & $\mathrm{p}<0,279$ \\
\hline Female $n=\mathbf{1 7 0}$ of 164 versus $n=4$ of 7 & $\mathrm{p}<0,121$ & $\mathrm{p}<0,582$ & $\mathrm{p}<0,588$ \\
\hline Male $n=64$ of 164 versus $n=3$ of 7 & $\mathrm{p}<0,672$ & $\mathrm{p}<0,193$ & $\mathrm{p}<0,221$ \\
\hline
\end{tabular}

Table 2: Statistical correlations ("p" values of significance) between female and male RA patients associated with DM, Ath, $\mathrm{HT}, \mathrm{Tb}, \mathrm{mTb}$, mTu or complicated by AV, AAa, SI (including PA or SV).

Glossary to Table 2:

RA: Rheumatoid Arthritis; Lethal: allied disorder or RA related complication with lethal outcome

Associated (accompanying) disease: important comorbidity without direct causal role in death; DM: type 2 Diabetes Mellitus; Ath: Atherosclerosis; HT: HyperTension; Tb: Tuberculosis; mTb: miliary Tuberculosis; mTu: malignant Tumors; AV: systemic Autoimmune Vasculitis; AAa: systemic AA amyloidosis; CI: Cardiac Insufficiency with lethal outcome; SI: lethal Septic Infection; PA: Purulent Arthritis; SV: systemic Septic Vasculitis.

DM ( $\mathrm{n}=41)$ was associated with AV in 7, AAa in 6, CI in 4, SI in 6, PA in 3, and SV in none of 41 patients.

Ath $(\mathrm{n}=107)$ accompanied AV in 12 , AV (lethal) in 4, AAa in 12, AAa (lethal) in 4, CI in 5, SI in 9, PA in 3, SV in none of 107 patients. The relationship between Ath and
AV, AV (lethal), AAa, AAa (lethal), CI, SI, PA or SV was consequently inverse and mostly significant (Table 3 ).

Ath with lethal outcome $(n=61)$ went together AV in 3 and AAa in none of 61 patients. The relationship between Ath (with lethal outcome) and AV or AAa was inverse and significant (Table 3). In other words Ath (lethal) was not 


\section{Journal of Orthopedics \& Bone Disorders}

associated with AV (lethal), AAa (lethal), CI, SI, PA or SV (since a patient may have only one cause of death; the links were inverse and usually significant (Table 3).

HT ( $n=41)$ occurred with AV in 4, AV (lethal) in 2, AAa in 8 , AAa (lethal) in 3, CI in 2, SI in 3, PA in 1 , SV in none of 41 patients.

$\mathrm{Tb}(\mathrm{n}=28)$ coexisted with $\mathrm{AV}$ in $9, \mathrm{AV}$ (lethal) in 5 , AAa in 2, AAa (lethal) in none, CI in 3, SI in 5, PA in 1, SV in 1 of 28 patients.

mTb (n=9) accompanied AV in 4, AV (lethal) in 4, AAa in 2, AAa (lethal) in none, $\mathrm{CI}$ in $1, \mathrm{SI}$ in 2, PA in none, SV in 1 of 9 patients. There was a positive and significant correlation between $\mathrm{Tb}$ and $\operatorname{AV}\left(\chi^{2}=4.0188, \mathrm{p}<0.04\right)$ or $\mathrm{mTb}$ and AV $\left(\chi^{2}=4.2406, \mathrm{p}<0.03\right)$ (Table 3$)$. There was a very close connection between mTb and mortality of AVas well $\left(\chi^{2}=11.88, p<0.0005\right)$.

mTu (n=27) was observed with AV in 1, AAa in 4, CI in $1, \mathrm{SI}$ in $3, \mathrm{PA}$ in $1, \mathrm{SV}$ in none of 27 patients.

The links between allied disorders and the most important complications of RA, apart from the above mentioned positive and significant relationship of $\mathrm{Tb}$ and $\mathrm{mTb}$, were in most cases not significant and mainly inverse.

The statistical links ("p" values of significance) between allied disorders and prevalence or mortality of RA related complications are summarized in Table 3.

*asterisk indicates a negative value of associations' coefficient with inverse relationship.

\begin{tabular}{|c|c|c|c|c|c|c|c|}
\hline $\begin{array}{l}\text { Allied disorders in } \\
\text { RA }\end{array}$ & DM 41 of 234 & $\begin{array}{c}\text { Ath } \\
\mathbf{n}=\mathbf{1 0 7} \text { of } \\
234\end{array}$ & $\begin{array}{c}\text { Ath } \\
\text { (lethal) } \\
n=61\end{array}$ & $\begin{array}{c}\text { HT } 41 \text { of } \\
234\end{array}$ & $\begin{array}{c}\text { Tb } 28 \text { of } \\
234\end{array}$ & $\begin{array}{c}\text { mTb } 9 \\
\text { of } 28\end{array}$ & $\begin{array}{c}\text { mTu } 27 \\
\text { of } 234\end{array}$ \\
\hline \multicolumn{8}{|l|}{ Complications of RA } \\
\hline $\mathbf{A V} \mathbf{n}=\mathbf{4 3}$ of 234 & $\chi^{2}=0.05 *, p<0.81$ & $\begin{array}{c}\chi^{2}=6.74 * \\
\mathbf{p}<0.009\end{array}$ & $\begin{array}{l}\chi^{2}=15.92 *, \\
\mathbf{p}<0.00007\end{array}$ & $\begin{array}{c}\chi^{2}=2.46 * \\
p<0.11\end{array}$ & $\begin{array}{r}\chi^{2}=4.02, \\
p<0.04\end{array}$ & $\begin{array}{c}\chi^{2}=4.24 \\
p<0.03\end{array}$ & $\begin{array}{c}\chi^{2}=3.34 * \\
p<0.07\end{array}$ \\
\hline AV lethal $\mathbf{n}=\mathbf{2 4}$ of 43 & $\chi^{2}=1.52 *, \mathrm{p}<0.21$ & $\begin{array}{r}\chi^{2}=9.09 * \\
\mathbf{p}<0.002\end{array}$ & $\begin{array}{c}\chi^{2}=7.98 * \\
\mathbf{p}<0.004\end{array}$ & $\begin{array}{c}\chi^{2}=0.93 * \\
\mathrm{p}<0.33\end{array}$ & $\begin{array}{c}\chi^{2}=1.99 \\
\mathrm{p}<0.15\end{array}$ & $\begin{array}{c}\chi^{2}=11.88 \\
, \mathbf{p}<0.00 \\
05\end{array}$ & $\begin{array}{c}\chi^{2}=0.73 * \\
p<0.39\end{array}$ \\
\hline AAa $n=48$ of 234 & $\chi^{2}=1.05 *, p<0.30$ & $\begin{array}{c}\chi^{2}=10.45 * \\
, p<0.001\end{array}$ & $\begin{array}{c}\chi^{2}=11.04 * \\
p<0.0008\end{array}$ & $\begin{array}{c}\chi^{2}=0.03 * \\
\mathrm{p}<0.86\end{array}$ & $\begin{array}{l}\chi^{2}=2.61 * \\
, p<0.10\end{array}$ & $\begin{array}{l}\chi^{2}=0.08 * \\
, \mathrm{p}<0.77\end{array}$ & $\begin{array}{c}\chi^{2}=0.60 * \\
p<0.43\end{array}$ \\
\hline $\begin{array}{c}\text { AAa lethal } \mathbf{n}=\mathbf{2 4} \text { of } \\
48\end{array}$ & $\chi^{2}=0.38 *, p<0.53$ & $\begin{array}{c}\chi^{2}=5.83 * \\
p<0.01\end{array}$ & $\begin{array}{c}\chi^{2}=6.30 * \\
p<0.01\end{array}$ & $\begin{array}{c}\chi^{2}=0.00 * \\
\mathrm{p}<0.99\end{array}$ & $\begin{array}{l}\chi^{2}=1.86 * \\
, \mathrm{p}<0.17\end{array}$ & $\begin{array}{l}\chi^{2}=0.10 * \\
, \mathrm{p}<0.74\end{array}$ & $\begin{array}{c}\chi^{2}=1.75 *, \\
\mathrm{p}<0.18\end{array}$ \\
\hline CI $\mathbf{n = 1 5}$ of 234 & $\chi^{2}=0.92, p<0.33$ & $\begin{array}{c}\chi^{2}=0.99 * \\
\mathrm{p}<0.31\end{array}$ & $\begin{array}{c}\chi^{2}=4.29 * \\
\mathbf{p}<0.03\end{array}$ & $\begin{array}{c}\chi^{2}=0.00 * \\
\mathrm{p}<0.92\end{array}$ & $\begin{array}{c}\chi^{2}=0.33 \\
\mathrm{p}<0.56\end{array}$ & $\begin{array}{c}\chi^{2}=0.01 \\
p<0.91\end{array}$ & $\begin{array}{c}\chi^{2}=0.03 * \\
\mathrm{p}<0.84\end{array}$ \\
\hline SI $\mathbf{n}=\mathbf{3 3}$ of 234 & $\chi^{2}=0.01, p<0.91$ & $\begin{array}{c}\chi^{2}=5.27 * \\
\mathbf{p}<0.02\end{array}$ & $\begin{array}{c}\chi^{2}=12.05 * \\
p<0.0005\end{array}$ & $\begin{array}{c}\chi^{2}=1.27 * \\
\mathrm{p}<0.25\end{array}$ & $\begin{array}{c}\chi^{2}=0.37 \\
p<0.54\end{array}$ & $\begin{array}{c}\chi^{2}=0.05 \\
p<0.82\end{array}$ & $\begin{array}{c}\chi^{2}=0.03 * \\
\mathrm{p}<0.85\end{array}$ \\
\hline PA $\mathbf{n = 1 5}$ of 33 & $\chi^{2}=0.00, p<0.92$ & $\begin{array}{c}\chi^{2}=3.23 * \\
\mathrm{p}<0.07\end{array}$ & $\begin{array}{c}\chi^{2}=4.29 * \\
p<0.03\end{array}$ & $\begin{array}{c}\chi^{2}=0.78 * \\
\mathrm{p}<0.37\end{array}$ & $\begin{array}{l}\chi^{2}=0.05 * \\
, \mathrm{p}<0.80\end{array}$ & $\begin{array}{l}\chi^{2}=0.01 * \\
, \mathrm{p}<0.91\end{array}$ & $\begin{array}{c}\chi^{2}=0.03 * \\
\mathrm{p}<0.84\end{array}$ \\
\hline $\mathbf{S V} \mathbf{n}=7$ of 33 & $\chi^{2}=0.23 *, p<0.62$ & $\begin{array}{c}\chi^{2}=4.32 *, \\
p<0.03\end{array}$ & $\begin{array}{c}\chi^{2}=1.34 * \\
p<0.24\end{array}$ & $\begin{array}{c}\chi^{2}=0.53 * \\
\mathrm{p}<0.46\end{array}$ & $\begin{array}{c}\chi^{2}=0.15 \\
p<0.68\end{array}$ & $\begin{array}{c}\chi^{2}=0.21 \\
p<0.64\end{array}$ & $\begin{array}{c}\chi^{2}=0.13 *, \\
\mathrm{p}<0.71\end{array}$ \\
\hline
\end{tabular}

Table 3: The statistical links ("p" values of significance) between allied disorders and prevalence or mortality of RA related complications.

\section{Glossary to Table 3:}

RA: Rheumatoid Arthritis $\mathrm{n}=234$

Ath: Atherosclerosis $n=107$ of 234 , with lethal outcome $n=61$ of 107

HT: HyperTension $n=41$ of 234

DM: adult type 2 Diabetes Mellitus $n=41$ of 234

Tb: Tuberculosis $n=28$ of 234

mTb: Tuberculosis with miliary dissemination $n=9$ of 234

mTu: malignantTumour $\mathrm{n}=27$ of 234

AV: systemic Autoimmune Vasculitis $n=43$ of 234 , with lethal outcome $n=24$ of 43

AAa: AA amyloidosis $n=48$ of 234 , with lethal outcome $n=20$ of 48 


\section{Journal of Orthopedics \& Bone Disorders}

CI: Cardiac Iinsufficiency caused exclusively by endo-, myo- or pancarditis n=15 of 234

SI: Lethal Septic Infection $n=33$ of 234

SV: systemic Septic Vasculitis $n=7$ of 33

PA: Purulent Arthritis $n=15$ of 33

The most important RA related complications and comorbidities are demonstrated in Figures 1-10 including but not limited to all possibilities.

Figures 1-3 show different types and stages of autoimmune coronary vasculitis, Figures 4-5 early and late stages of amyloid a deposition in adrenal gland, Figures 6-7 fibrocaseous and exudative mTb, and Figures
8-10 the most frequent mTu (bronchoalveolar carcinoma) in RA.

Original magnifications correspond to the $24 \times 36 \mathrm{~mm}$ transparency slide; the correct height: width ratio is 2:3. The printed size may be different; therefore it is necessary to indicate the original magnifications.
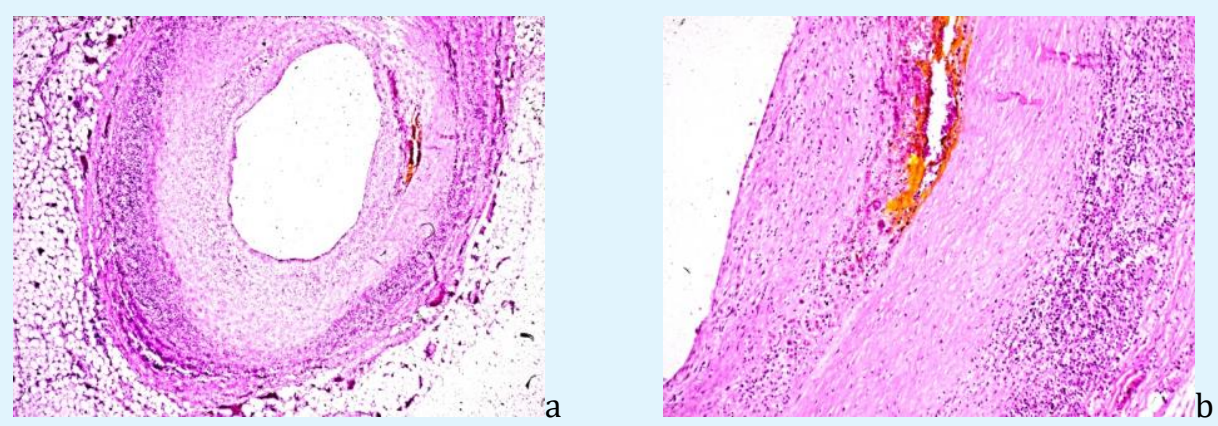

Figure 1: RA, heart, main (medium size) coronary artery, non-specific subchronic vasculitis Sectorial accentuated lympho-plasmocellular infiltration and moderate fibromuscular intimal proliferation.

More than 21 days old hemorrhage, with hematoidine crystals at the border of intima and media.

(a) HE, x20 (b) same as (a) x50
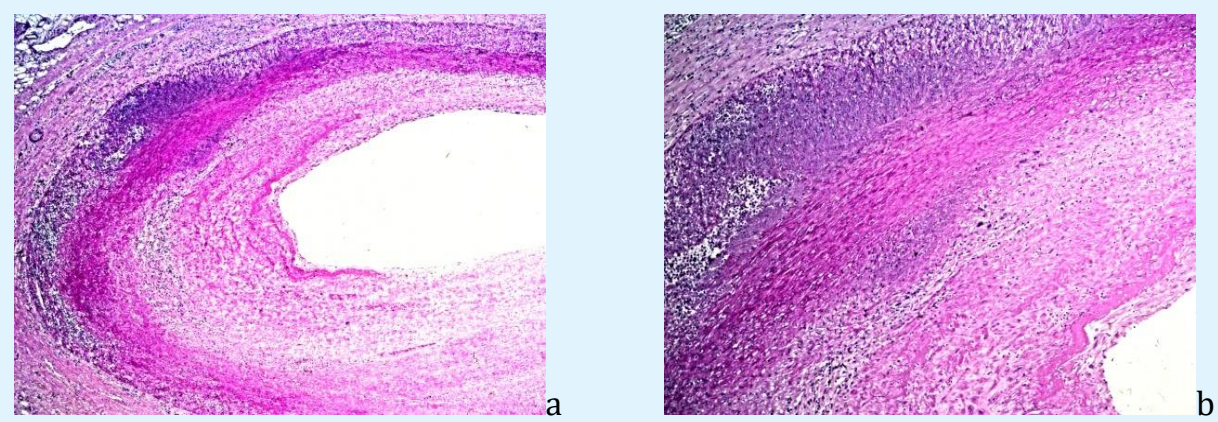

Figure 2: RA, heart, main (medium size) coronary artery Subacute-subchronic vasculitis with incipient (early stage) rheumatoid nodule in media and adventicia, sectorial accentuated leuco-lympho-plasmocellular infiltration and moderate fibromuscular intimal proliferation.

(a) HE, x20 (b) same as (a) x50 


\section{Journal of Orthopedics \& Bone Disorders}

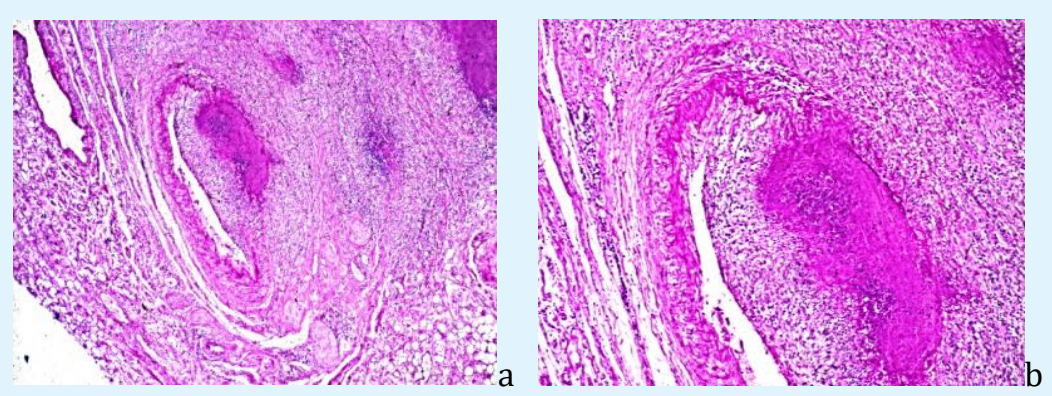

Figure 3: RA, heart, main (medium size) subepicardial coronary artery, subchronic nodular vasculitis Typical rheumatoid nodule in media and adventicia, sectorial accentuated granulomatous transformation of vessel wall and moderate fibromuscular intimal proliferation.

(a) HE, x20 (b) same as (a) x50
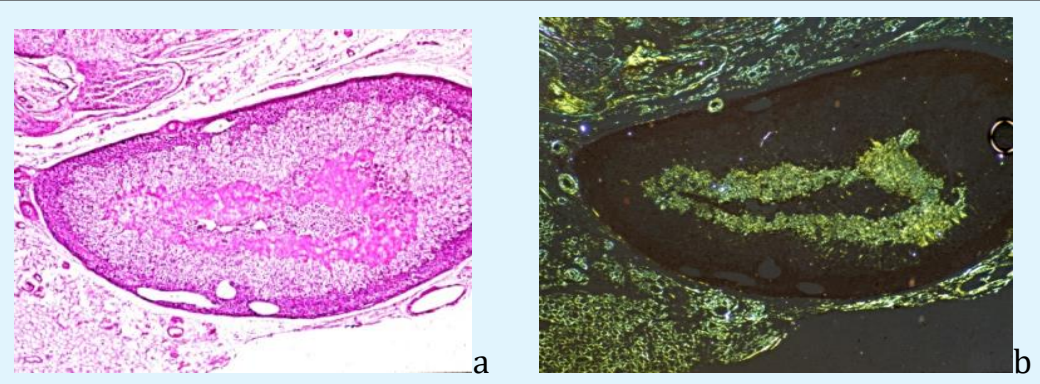

Figure 4: RA, adrenal gland and periadrenal fat tissue, early stage of systemic secondary AA amyloidosis Amyloid A deposited within reticular zone of adrenal gland, in the wall of periadrenal blood vessels (arterioles) and along reticular and collagen fibers.

(a) HE, x 50, (b) same as (a) Congo red staining, without alcoholic differentiation, covered with gum arabic. Viewed under polarized light $\mathrm{x} 50$
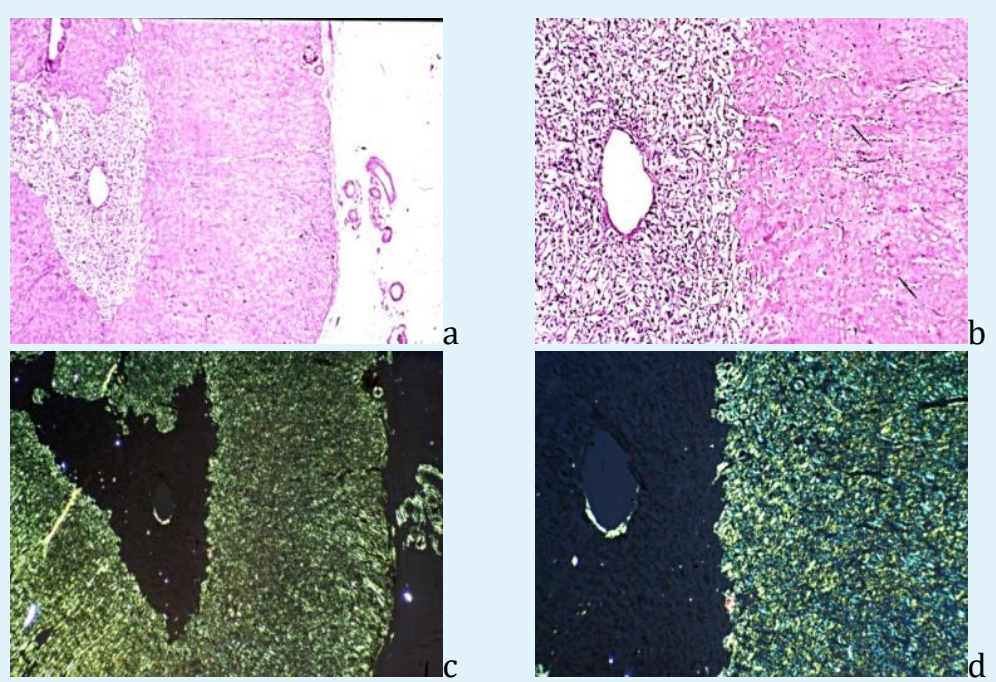

Figure 5: RA, adrenal gland and periadrenal fat tissue, late stage of systemic secondary AA amyloidosis Amyloid A deposited within the reticular, fascicular and glomerular zones of adrenal cortex, involving periadrenal blood vessels, reticular and collagen fibers

(a) HE, x 50, (b) same as (a) x125, (c) same as Figure (a) Congo red staining viewed under polarized light, x50, (d) same as Figure ( $b$ and c) Congo red staining viewed under polarized light, x125 


\section{Journal of Orthopedics \& Bone Disorders}
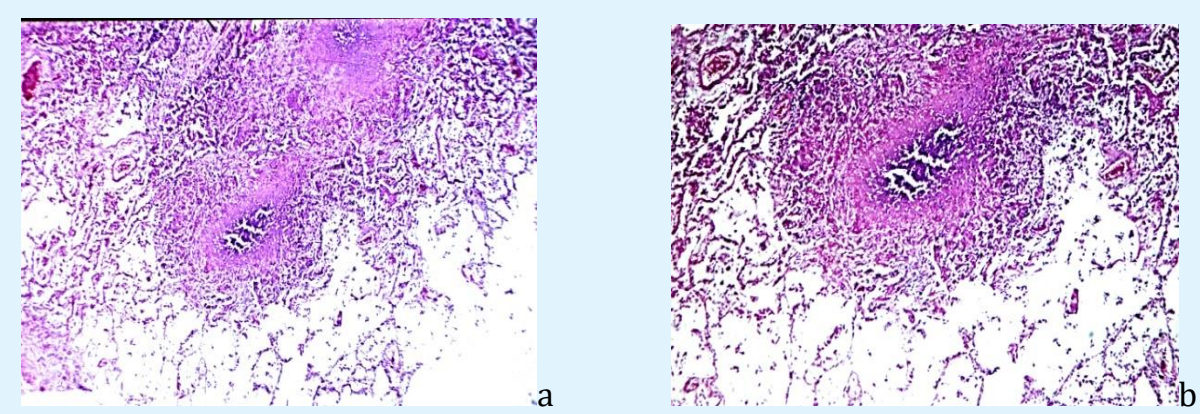

Figure 6: RA, miliary disseminated caseous tuberculosis in the lung (a) HE, x 50, (b) same as (a) x125
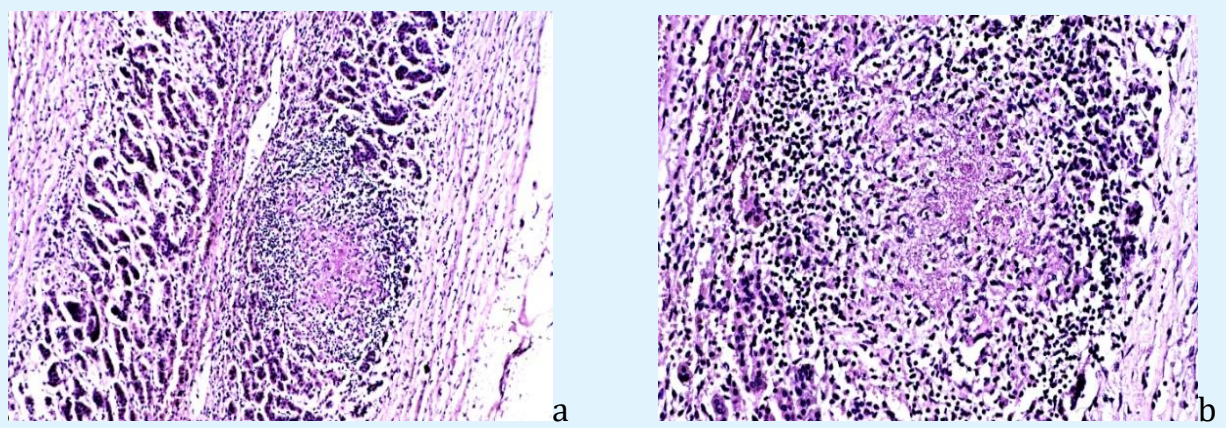

Figure 7: RA, exudative miliary epithelioid granulomas in atrophic suprarenal gland (a) HE, x 50, (b) same as (a) x125

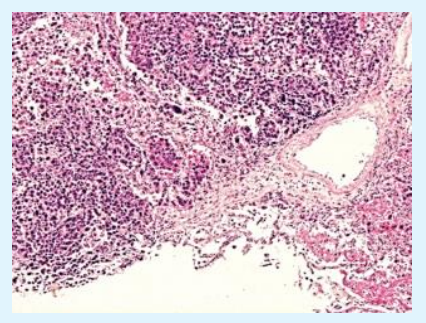

a

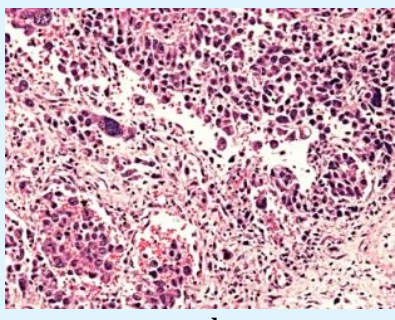

$\mathrm{b}$

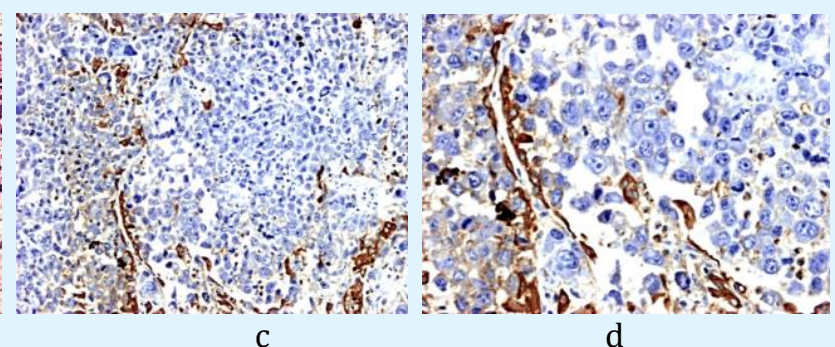

C

Figure 8: RA, lung, undifferentiated bronchoalveolar carcinoma Irregular spaces separated by fibrotic septa, and enveloped by tall partly columnar epithelium

(a) HE, x 40, (b) same as (a) x100, (c) Anti-human epithelial membrane antigen (mono/DAKO N1504), x 100 (d) same as (c) $\mathrm{x} 200$ 


\section{Journal of Orthopedics \& Bone Disorders}

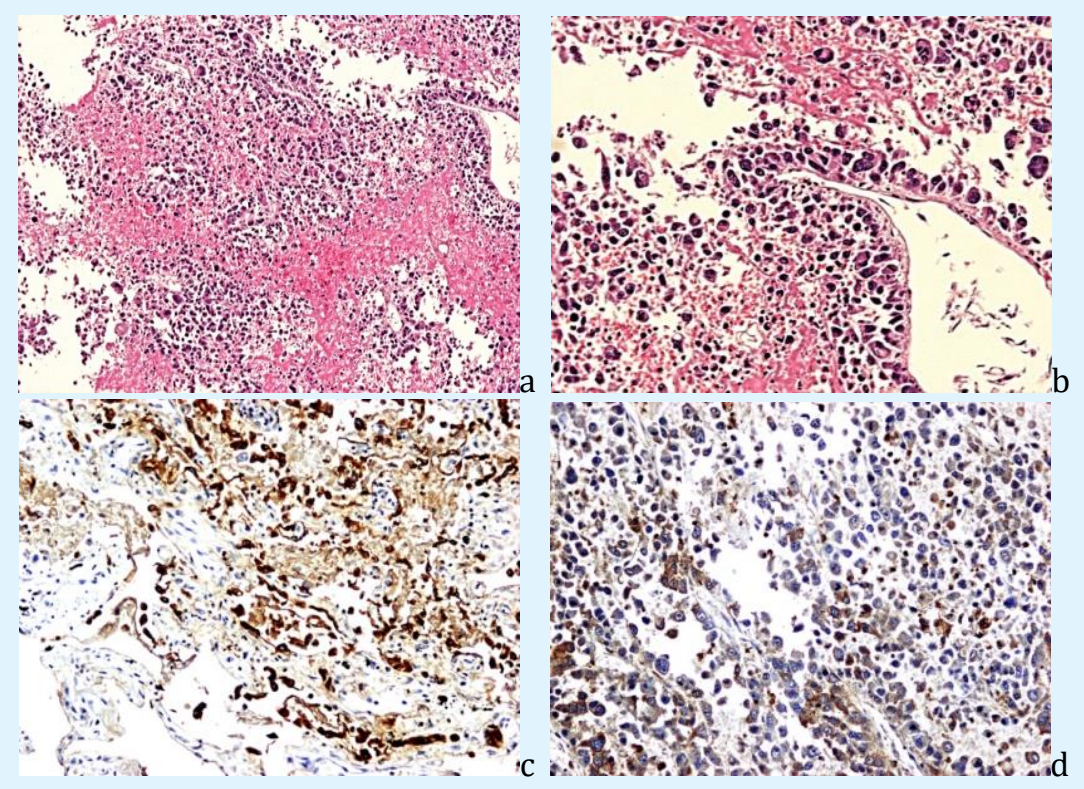

Figure 9: RA, lung, undifferentiated bronchoalveolar carcinoma Irregular spaces separated by fibrotic septa, and enveloped by tall columnar epithelium.

(a) HE, $x$ 40, (b) same as (a) x100, (c) Anti-human epithelial membrane antigen (mono/DAKO N1504), x 100, (d) Antihuman carcinoembrionic antigen 1:100 (mono/DAKO N1503) x100

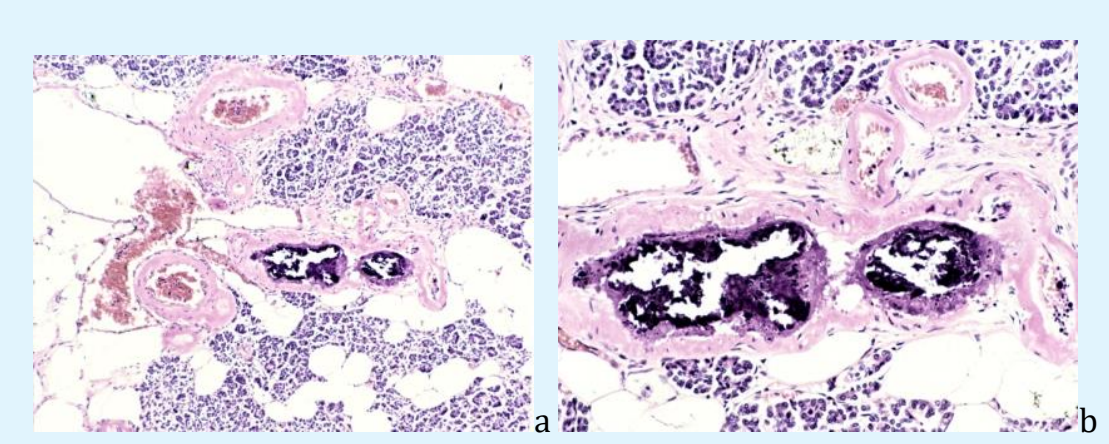

Figure 10: RA, DM, pancreas, severe atherosclerosis involving small arteries

(a) HE, x 50, (b) same as (a) x125

\section{Discussion}

Severe atherosclerosis was present nearly in half, in $107(45.72 \%)$ of 234 RA patients, and led to death in more than half $61(57.01 \%)$ of them. Ath was the most important allied disorder leading to death in RA.

The mean age of atherosclerotic female and male RA patients was higher than the mean age of the others or of the total population, and RA started consequently later in these patients. RA associated with Ath may represent a special subgroup of RA patients with a better prognosis, which may correspond to the clinically benign elderlyonset or late-onset RA [11]. The negative correlations between allied disorders and RA related complications represent an inverse relationship between them. The high prevalence of allied disorder suggests a rarer (less common) occurrence of RA related complication. Ath with 


\section{Journal of Orthopedics \& Bone Disorders}

lethal outcome surmises an especially lower risk for RA related complications $(\mathrm{AV}, \mathrm{AV}$ lethal, $\mathrm{AAa}, \mathrm{AAa}$ lethal, $\mathrm{CI}$, SI or PA), based on the strong and significant but negative correlations between them. With other words, the most important complications of RA are presumably less frequent in atherosclerotic RA patients.

The negative correlation between Ath and CI shows that cardiac insufficiency in our patients' group was caused by endo-, myo-, epi- or pancarditis, and polyserositis with or without interstitial pneumonitis, which complicated RA earlier and in younger patients (without prominent atherosclerosis).

The lower mean age of RA patients complicated by lethal AAa (56.80 years versus 66.25; $\mathrm{p}<0.032$ ) and the early onset of disease ( 40.33 years versus 51.02 ; $p<0.049$ ) in these patients indicate also, that the most dangerous complications of RA involve mainly the younger generation, which was also supported by the strong negative and significant correlations to Ath $\left(\chi^{2}=5.83^{*}\right.$, $\mathrm{p}<0.01)$ or to Ath with lethal outcome $\left(\chi^{2}=6.30^{*}, \mathrm{p}<0.01\right)$.

Septic complication including PA led to early death of the patients (SI: 62.33 and PA: 59.47 years versus 66.25; $\mathrm{p}<0.028$ and $\mathrm{p}<0.004)$, which also showed a distinct difference in women (SI: 61.35 and PA: 58.20 years versus 66.31; $\mathrm{p}<0.031$ and $\mathrm{p}<0.005)$. The strong negative and significant relationship between Ath and SI $\left(\chi^{2}=5.27\right.$, $\mathrm{p}<0.02)$ or PA $\left(\chi^{2}=3.23^{*}, \mathrm{p}<0.07-\mathrm{NS}\right)$, and between Ath with lethal outcome and SI $\left(\chi^{2}=12.05^{*}, \mathrm{p}<0.0005\right)$ or PA $\left(\chi^{2}=4.29 *, p<0.03\right)$ referred again to the explicit involvement of younger people.

Diabetes and hypertension are the basic risk factors of atherosclerosis and its complications. DM and HT raise the prevalence of Ath, cardiovascular diseases, limited renal function, progressive endothelial dysfunction, higher intraocular pressure, decreased erectile function etc. independently from each other, and the risk of these increases in case of coexistence [12-14].

According to the literature, DM is often associated with HT, and it is also mentioned in several studies as an evidence statement [15-18]. According to our data DM, HT or Ath did not influece the prevalence and mortality of RA related complications, and the clinically well controlled DM or HT does not diminish the chances of survival.

Tuberculosis is one of the most important associated diseases accompanying RA [3]. The positive and significant correlation between $\mathrm{Tb}$ and $\operatorname{AV}\left(\chi^{2}=4.02, \mathrm{p}<\right.$ $0.04)$ or $\mathrm{mTb}$ and $\mathrm{AV}\left(\chi^{2}=4.24, \mathrm{p}<0.03\right)$ suggest a positive role of tuberculosis on the prevalence and mortality of autoimmune vasculitis in RA. The presence of $\mathrm{Tb}$ (especially of its fibrocaseous form) or endogenous exacerbation and miliary dissemination of tuberculosis $(\mathrm{mTb})$ increases, promotes, and facilitates the risk of $\mathrm{AV}$ and modifies the histological type of vasculitis $[19,20]$. The significant connection between $\mathrm{mTb}$ and mortality of $\operatorname{AV}\left(\chi^{2}=11.88, p<0.0005\right)$ means an increased risk of lethal outcome. This statement was also supported by the late and collateral (parallel) onset of RA in patients with mTb (59.38 years versus 51.02; $<<0.033$ ) and AV (56.85 years versus $51.02 ; \mathrm{p}<0.037$ ) compared these to the total population. The tendency was the same and especially pronounced in females with mTb (58.71 years versus 50.46; $\mathrm{p}<0.033$ ) and with AV (58.04 years versus 50.46; $\mathrm{p}<0.022)$.

Published data indicate that the overall risk of malignancy (especially prevalence of lymphomas and lung cancer) is higher in RA, compared with the general population [21,22]. According to Buchbinder, et al. the incidence of malignancy was low in an Australian RA patients' cohort and anti-tumour necrosis factor treatment did not increase the risk of malignancy. Only the incidence of melanoma increased in comparison with the general population [23].

According to our data mTu did not influence the prevalence and mortality of RA related complications.

The prevalence and mortality of malignant tumors in pertinent literature and our RA autopsy population is summarized in Table 4.

\begin{tabular}{|c|c|c|c|c|}
\hline \multirow{2}{*}{ Authors } & \multirow{2}{*}{ Year of Publication-[References] } & \multirow{2}{*}{ No of Autopsy } & \multicolumn{2}{|c|}{ Tumor } \\
\cline { 3 - 5 } & & & Prevalence & Mortality \\
\cline { 3 - 5 } & & 23 & N - \% & N - \% of Total \\
\hline Bayles & $1943[24]$ & 30 & ND & $\mathbf{2}$ of $23-\mathbf{8 . 7 \%}$ \\
\hline Baggenstoss and Rosenberg & $1943[25]$ & 33 & ND & $\mathbf{1}$ of $30-\mathbf{3 . 3 \%} 33-\mathbf{6 . 1 \%}$ \\
\hline Young and Schwedel & $1944[26]$ & 27 & ND & $\mathbf{4}$ of $27-\mathbf{1 4 . 8 \%}$ \\
\hline Bywaters & $1950[27]$ & 45 & ND & $\mathbf{1}$ of $45-\mathbf{2 . 2 \%}$ \\
\hline Gedda & $1955[28]$ & \multicolumn{2}{|c}{}
\end{tabular}

Bely M and Apathy A. Allied Disorders and Complications of Rheumatoid Arthritis - A Statistical Comorbidity Study of 234 Autopsy Patients. J Ortho Bone Disord 2019, 3(1): 000174. 


\section{Journal of Orthopedics \& Bone Disorders}

\begin{tabular}{|c|c|c|c|c|}
\hline Goehrs, et al. & $1960[29]$ & 36 & ND & 4 of 36- 11.1\% \\
\hline Lebowitz & $1963[30]$ & 62 & ND & 6of 62- 9.7\% \\
\hline Gardner & $1972[31]$ & 142 & $\mathbf{2 4 - 1 6 . 9 \%}$ & ND \\
\hline Vroninks, et al. & $1973[32]$ & 62 & ND & $\mathbf{7}$ of $62-\mathbf{1 1 . 3 \%}$ \\
\hline Rainer, et al. & $1978[33]$ & 79 & ND & $\mathbf{2}$ of $79-\mathbf{2 . 5 3 \%}$ \\
\hline Lindahl & $1984[34]$ & 82 & ND & $\mathbf{3}$ of $82-\mathbf{3 . 7 \%}$ \\
\hline Suzuki, et al. & $1994[35]$ & 81 & ND & $\mathbf{5}$ of $81-\mathbf{6 . 2 \%}$ \\
\hline Bély and Apáthy & $1998[36]$ & 161 & $\mathbf{1 3 - 8 . 1 \%}$ & $\mathbf{7}$ of $13-\mathbf{4 . 4 \%}$ \\
\hline Bély and Apáthy & $2003[37]$ & $161^{*}$ & $\mathbf{1 5 - 9 . 3 \%}$ & $\mathbf{7}$ of $15-4.4 \%$ \\
\hline Bély and Apáthy & $2005[38]$ & $\mathbf{2 3 4} *$ & $\mathbf{2 7 - 1 1 . 5 \%}$ & 12 of $27-6.4 \%$ \\
\hline
\end{tabular}

Table 4: Literature on the morbidity and mortality of malignant tumors in autopsied RA patients.

\section{Glossary to Table 4}

ND: no data

*Re-evaluated data, including surgically removed tumors (no tumor at autopsy)

\section{Conclusion}

The consequently inverse and (in most cases) significant correlation between atherosclerosis and autoimmune vasculitis, amyloidosis or sepsis shows that the prevalence or mortality of AV, AAa and SI was not influenced by Ath. RA patients with Ath may represent a special group, characterized by lower incidence of SV, AAa, $\mathrm{SI}, \mathrm{CI}$, and carry a better prognosis. Ath is basically an agedependent phenomenon, characteristically present in RA patients with advanced age, while AV, AAa (with or without lethal outcome) and SI are complications of RA, and characterize severe forms of disease, mostly in younger patients and with an earlier onset (without pronounced atherosclerosis).

The positive and significant correlation between $\mathrm{Tb}$ and $\operatorname{AV}\left(\chi^{2}=4.02, \mathrm{p}<0.04\right)$ or $\mathrm{mTb}$ and $\operatorname{AV}\left(\chi^{2}=4.24, \mathrm{p}<\right.$ 0.03 ) suggest a positive influence of $\mathrm{Tb}$ or $\mathrm{mTb}$ on the prevalence of vasculitis, e.g. the presence of $\mathrm{Tb}$ or endogenous exacerbation and miliary dissemination of $\mathrm{Tb}$ may promote the AV; and modify the histological type of vasculitis $[19,20]$. The significant connection between mTb and mortality of $\mathrm{AV}\left(\chi^{2}=11.88, \mathrm{p}<0.0005\right)$ indicates an increased risk of lethal outcome.

Finalizing the results of interaction between coexistent allied disorders and complications of RA it may be concluded that there is a more or less close link between them. The knowledge of these complications and the likelihood of their occurrence should be considered when management, particularly therapeutic decisions are made: "one sees what one knows".

\section{References}

1. Jeong H, Baek SY, Kim SW, Eun YH, Kim IY, et al. (2017) Correction: Comorbidities of rheumatoid arthritis: Results from the Korean National Health and Nutrition Examination Survey. PLoS One 12(5): e0178309.

2. Van den Hoek J, Boshuizen HC, Roorda LD, Tijhuis GJ, Nurmohamed MT, et al. (2017) Mortality in patients with rheumatoid arthritis: a 15-year prospective cohort study. Rheumatol Int 37(4): 487-493.

3. Bély M, Ágnes A (2013) Clinical pathology of rheumatoid arthritis: Cause of death, lethal complications and associated diseases in rheumatoid arthritis, pp: 1-440.

4. Arnett FC, Edworthy SM, Bloch DA, McShane DJ, Fries JF, et al. (1988) The American Rheumatism Association 1987 revised criteria for the classification of rheumatoid arthritis. Arthritis Rheum 31(3): 315324.

5. Lentner C (1982) "Statistical methods". In Geigy scientific tables, 8th revised and enlarged ed: CibaGeigy Limited, Basle, Switzerland, 2: 227.

6. Bély M, Apáthy Á (2017) Myocardial necrosis caused by systemic vasculitis or atherosclerosis in rheumatoid arthritis-A postmortem clinicopathologic study of 161 patients. EC Cardiology 3(3): 74-91.

7. Apáthy Á, Bély M (2016) AB0528 Organ Involvement with Systemic Vasculitis of Autoimmune and of Septic Origin-A Comparative Postmortem Study of 38 


\section{Journal of Orthopedics \& Bone Disorders}

Rheumatoid Arthritis Patients. Annals of the Rheumatic Diseases 75(S2): 1096.

8. Romhányi G (1971) Selective differentiation between amyloid and connective tissue structures based on the collagen specific topo-optical staining reaction with Congo red. Virchows Arch A Pathol Pathol Anat 354(3): 209-22.

9. Bély M, Makovitzky J (2006) Sensitivity and specificity of Congo red staining according to Romhányi- Comparison with Puchtler's or Bennhold's methods. Acta Histochemica 108(3): 175-180.

10. Bély M (2006) Histochemical differential diagnosis and polarization optical analysis of amyloid and amyloidosis. ScientificWorldJournal 6: 154-68.

11. Der Sarkissian C (2017) What You Need to Know About Elderly-Onset RA. WebMD Medical Reference, Reviewed by Carol DerSarkissian.

12. Park HY, Schumock GT, Pickard AS, Akhras K (2003) A structured review of the relationship between microalbuminuria and cardiovascular events in patients with diabetes mellitus and hypertension. Pharmacotherapy 23(12): 1611-1616.

13. Preik M, Kelm M, Rosen P, Tschope D, Strauer BE (2000) Additive effect of coexistent type 2 diabetes and arterial hypertension on endothelial dysfunction in resistance arteries of human forearm vasculature. Angiology 51(7): 545-554.

14. Hennis A, Wu SY, Nemesure B, Leske MC (2003) Hypertension, diabetes, and longitudinal changes in intraocular pressure. Ophthalmology 110(5): 908914.

15. Basile JN, Lackland DT, Basile JM, Riehle JE, Egan BM (2004) A statewide primary care approach to cardiovascular risk factor control in high-risk diabetic and nondiabetic patients with hypertension. Journal of Clinical Hypertension 6(1): 18-25.

16. Bouhanick B, Laboureau Soares BS, Marre M (2000) Hypertension and diabetes. Archives des maladies du coeur et des vaisseaux 93: 1429-1434.

17. Sowers JR, Epstein M, Frohlich ED (2001) Diabetes, hypertension, and cardiovascular disease: an update. Hypertension 37(4): 1053-1059.
18. El Atat F, McFarlane SI, Sowers JR (2004) Diabetes, hypertension, and cardiovascular derangements: pathophysiology and management. Curr Hyperten Rep 6(3): 215-223.

19. Bély M, Apáthy Á (2013) AB0644 Mortality of tuberculosis in rheumatoid arthritis-a retrospective clinicopathologic study of 234 autopsy patients. Annals of the Rheumatic Diseases 72(S3): A986-A986.

20. Apáthy Á, Bély M (2013) THU0437 Disease Modifying Effect of Tuberculosis on Coexistent Systemic Vasculitis in Rheumatoid Arthritis-A Retrospective Clinicopathologic Study of 234 Autopsy Patients. Annals of the Rheumatic Diseases 72(S3): A312.

21. Smitten AL, Simon TA, Hochberg MC, Suissa S (2008) A meta-analysis of the incidence of malignancy in adult patients with rheumatoid arthritis. Arthritis Res Ther 10(2): R45.

22. Simon TA, Thompson A, Gandhi KK, Hochberg MC, Suissa S (2015) Incidence of malignancy in adult patients with rheumatoid arthritis: a meta-analysis. Arthritis Res Ther 17: 212.

23. Buchbinder R, Van Doornum S, Staples M, Lassere M, March L (2015) Malignancy risk in Australian rheumatoid arthritis patients treated with antitumour necrosis factor therapy: analysis of the Australian Rheumatology Association Database (ARAD) prospective cohort study. BMC Musculoskelet Disord 16: 309.

24. Bayles TB (1943) Rheumatoid arthritis and rheumatic heart disease in autopsied cases. American Journal of Medical Sciences 205: 42-48.

25. Baggenstoss AH, Rosenberg EF (1943) Visceral lesions associated with chronic infectious (rheumatoid) arthritis. Archives of Pathology 35: 503-516.

26. Young D, Schwedel JB (1944) The heart in rheumatoid arthritis. American Heart Journal 28(1): $1-23$.

27. Bywaters EGL (1950) The relation between heart and joint disease including "rheumatoid heart disease" and chronic post-rheumatic arthritis (type Jaccoud). Br Heart J 12(2): 101-131. 


\section{Journal of Orthopedics \& Bone Disorders}

28. Gedda PO (1955) On amyloidosis and other causes of death in Rlicurnatoid arthritis. Acta Medica Scandinavica 150(6): 443-452.

29. Goehrs HR, Baggenstoss AH, Slocumb CH (1960) Cardiac lesions in rheumatoid arthritis. Arthritis and Rheumatism 3: 298-308.

30. Lebowitz WB (1963) The heart in rheumatoid arthritis (Rheumatoid disease). A clinical and pathological study of sixty-two cases. Annals of Internal Medicine 58: 102-123.

31. Gardner DL (1972) The pathology of rheumatoid arthritis. In: Edward Arnold, (Ed.), Causes of death, pp: 183-197.

32. Vroninks Ph, Cats A, Eulderink F, Goslinks J (1973) Heart defects in rheumatoid arthritis, in particular pericarditis. Nederlands Tijdschrift voor Geneeskunde 117: 10-17.

33. Rainer F, Klein G, Schmid P, Härringer M (1978) Untersuchungen über Art und Häufigkeit der Todesursachen bei chronischer Polyarthritis. Zeitschrift für Rheumatologie 37: 335-341.
34. Lindahl BI (1984) The reliability of Swedish mortality statistics for rheumatoid arthritis. Scandinavian Journal of Rheumatology 13(4): 289-296.

35. Suzuki A, Ohosone Y, Obana M, Mita S, Matsuoka Y, et al. (1994) Cause of death in 81 autopsied patients with rheumatoid arthritis. Journal of Rheumatology 21(1): 33-36.

36. Bély M, Apáthy Á (1998) Daganatos megbetegedések rheumatoid arthritisben. Orvosi Hetilap 139: 25672574.

37. Bély M, Apáthy Á (2004) Tumors in reumatoid arthritis-A retrospective clinicopathologic study of 161 autopsy patients. Annals of the Rheumatic Diseases 63(S1): 539.

38. Apáthy Á, Bély M (2004) Clinical and laboratory parameters, demographics and duration of disease associated with benign and malignant tumors in rheumatoid arthritis-A retrospective clinicopathologic study of 161 autopsy patients. Annals of the Rheumatic Diseases 63(1): 167-168. 